\section{Consers}

- Additional material is published online only. To view please visit the journal online (http://dx.doi.org/10.1136/ thoraxjnl-2017-209982).

Department of Pulmonary Medicine, VU University Medical Centre, Amsterdam, The Netherlands

Correspondence to Professor Dr Anton Vonk Noordegraaf, Department of Pulmonary Medicine, VU University Medical Centre, De Boelelaan 1117, Amsterdam 1081 HV, The Netherlands; a.vonk@vumc.nl

Received 11 January 2017 Revised 5 April 2017 Accepted 18 April 2017 Published Online First 5 May 2017

\section{CrossMark}

To cite: Botros L, Aman J, Bogaard HJ, et al. Thorax 2017;72:1164-1166.

\title{
Pulmonary hypertension with warm hands
}

\author{
Liza Botros, Jurjan Aman, Harm Jan Bogaard, Anton Vonk Noordegraaf
}

A 19-year-old woman of Moroccan descent presented with severe dyspnoea on exertion. She had difficulty walking stairs (New York Heart Association functional class 3) and accompanying symptoms included fatigue, palpitations and near collapse. She had no cough or wheezing, but mentioned severe and continuous menstrual bleeds since menarche without use of contraceptives. Her medical history included long-standing complaints of fainting, abdominal pains and chest pain, without a clear diagnosis. The family history included hypercholesterolaemia and venous thromboembolic disease (VTE). In fact, 1 year prior to this presentation, the patient was diagnosed with PE herself. Other than a temporary mild polycythaemia (haemoglobin concentration of $16 \mathrm{~g} / \mathrm{dL}$ ) no risk factors for VTE had been discovered at that time.

Physical examination showed a thin woman with a body mass index of $17 \mathrm{~kg} / \mathrm{m}^{2}$ (height $161 \mathrm{~cm}$ and weight $44 \mathrm{~kg}$ ). Her blood pressure was $82 / 51 \mathrm{~mm}$ $\mathrm{Hg}$, while her extremities appeared warm. Her heart rate was $91 \mathrm{bpm}$, the respiratory rate $16 / \mathrm{min}$ and oxygen saturation $\left(\mathrm{SpO}_{2}\right)$ 98\%. Heart and lungs appeared normal, but abdominal examination revealed overt hepatosplenomegaly. There were no signs of peripheral oedema, venous thrombosis or clubbing.

Routine blood chemistry showed a haemoglobin level of $16.0 \mathrm{~g} / \mathrm{dL}$, haematocrit $57 \%$, a mean corpuscular volume of 72 , reticulocyte index $18 \%$ together with a serum iron of $6.1 \mu \mathrm{mol} / \mathrm{L}$ and a ferritin of $7 \mu \mathrm{g} / \mathrm{L}$, suggestive for anaemia secondary to severe iron deficiency, most likely due to hypermenorrhoea. The N-terminal pro brain natriuretic peptide level was elevated to $196 \mathrm{pg} / \mathrm{mL}$. Thrombocytes, white blood cells, kidney function, liver enzymes and thyroid stimulating hormone were all within reference values (see online supplementary table S3). No abnormalities were noted on the chest radiograph; however, a transthoracic echocardiogram showed mild right ventricular (RV) dilatation and dysfunction, a tricuspid annular plane systolic excursion of $23 \mathrm{~mm}$, an estimated RV systolic pressure of $57 \mathrm{~mm} \mathrm{Hg}$ and right atrial pressure of $5 \mathrm{~mm} \mathrm{Hg}$. Furthermore, there was no evidence of paradoxical septal motion. Cardiac magnetic imaging (CMR) was performed which confirmed mild RV dysfunction with an RV ejection fraction of $47 \%$ (see online supplementary table $\mathrm{S} 1$ ). The RV appeared mildly dilated and hypertrophic, whereas no signs of valvular abnormalities or intracardiac shunts were noted. This pointed to a pulmonary cause of her RV dysfunction. Spirometry showed a total lung capacity of $3.97 \mathrm{~L}$ (4.84 L; 82\%), residual volume of $1.08 \mathrm{~L}(1.31 \mathrm{~L}$; $82 \%)$, FVC of $2.65 \mathrm{~L}(3.59 \mathrm{~L} ; 74 \%)$ and $\mathrm{FEV}_{1}$ of
1.75 L (3.13 L; 56\%). Carbon monoxide diffusion capacity (DLCO) was $97.64 \mu \mathrm{mol} / \mathrm{s} / \mathrm{kPa}(60 \%)$ and 6 min walking distance was $370 \mathrm{~m}$ with no drop in $\mathrm{SpO}_{2}$. Because of the suspicion of pulmonary hypertension (PH), a right heart catheterisation (RHC) was performed which confirmed $\mathrm{PH}$ with an elevated mean pulmonary artery pressure of $56 \mathrm{~mm} \mathrm{Hg}$, pulmonary arterial wedge pressure (PAWP) of $16 \mathrm{~mm} \mathrm{Hg}$ with a moderately elevated pulmonary vascular resistance (PVR) $492 \mathrm{dyn} \cdot \mathrm{s} / \mathrm{cm}^{5}$ and decreased systemic vascular resistance (SVR) $742 \mathrm{dyn} \cdot \mathrm{s} / \mathrm{cm}^{5}$ (see online supplementary table S2).

Pulmonologist 1: The differential diagnosis of $\mathrm{PH}$ is extensive. Causes for pulmonary arterial hypertension (PAH, WHO group 1) such as drugs, anorexins and toxins as well as portal hypertension were excluded. Although left heart conditions such as congenital cardiac defects and valve abnormalities were excluded by CMR, the PAWP was elevated which makes $\mathrm{PH}$ due to left disease still a possibility (WHO group 2). The DLCO was reduced and spirometry appeared abnormal, although the latter is probably a consequence of Caucasian reference values. The absence of abnormalities on chest imaging made chronic lung disease-related $\mathrm{PH}$ (WHO group 3) unlikely but additional imaging is needed. Given the history of $\mathrm{PE}$, chronic thromboembolic pulmonary hypertension (CTEPH, WHO group 4) was clearly suspected and should be investigated by ventilation/ perfusion scintigraphy (V/Q scan). Finally, given the presence of hepatosplenomegaly, WHO group $5 \mathrm{PH}$ (multifactorial mechanisms) is still a possibility although no additional findings point to this direction.

A V/Q scan and CT angiography showed no perfusion defects besides in the left lower lobe due to residual thrombi. There was no evidence of parenchymal lung disease. A diagnosis of inoperable CTEPH was made and the patient was started on treatment with bosentan (125 mg twice daily), tadalafil (40 mg once daily; off-label use) and oral anticoagulants as standard CTEPH treatment. After 1 year on treatment, there was no improvement in exercise tolerance and the fatigue was unaltered. A repeated RHC showed a cardiac output of 13.0 L/min, a PVR of $176 \mathrm{dyn} \cdot \mathrm{s} / \mathrm{cm}^{5}$, whereas the SVR was further decreased to $367 \mathrm{dyn} \cdot \mathrm{s} / \mathrm{cm}^{5}$. The PAWP remained elevated (see online supplementary table S2). Subsequently, the patient requested a second opinion in our $\mathrm{PH}$ expert centre for specialised advanced knowledge on all types of patients with PH.

Pulmonologist 2: A diagnosis of CTEPH may seem reasonable in a patient with $\mathrm{PH}$, a prior VTE and perfusion defects, but in this patient the diagnosis can be 


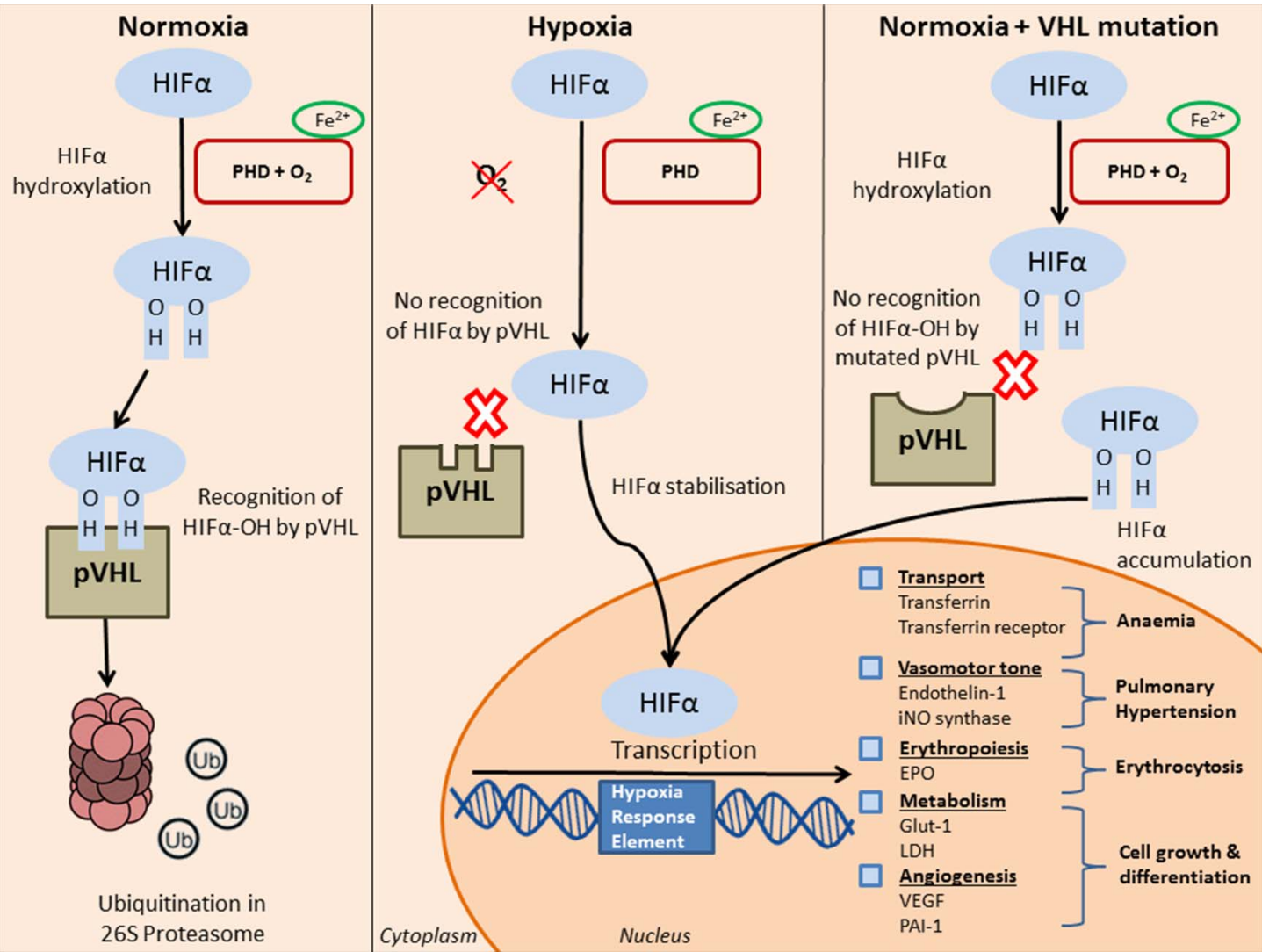

Figure 1 Protein Von Hippel-Lindau ( $\mathrm{pVHL}$ ) regulates hypoxia inducible factor- $\alpha$ (HIF $\alpha$ )-dependent gene transcription. Under normoxic conditions, prolyl hydroxylase (PHD) hydroxylates HIF $\alpha$ in the presence of iron. pVHL recognises hydroxylated HIF $\alpha$ leading to ubiquitination and degradation in the proteasome. In hypoxia, HIF $\alpha$ is not hydroxylated and therefore not recognised for degradation, resulting in transcription of HIF $\alpha$-dependent genes. When pVHL is mutated, HIF $\alpha$ is hydroxylated but not degraded, leading to accumulation of HIF $\alpha$. As a result, HIF $\alpha$ and hypoxia-dependent genes are constantly transcribed in normoxia. EPO, erythropoietin; iNO synthase, inducible nitric-oxide synthase; LDH, lactate dehydroxygenase; VEGF, vascular endothelial growth factor.

challenged. First, it seems difficult to explain the severity of her symptoms and haemodynamics by the minor perfusion defects seen on the V/Q scan, even though firm correlations between clot load and haemodynamics have never been established in CTEPH. Second, a diagnosis of CTEPH requires the presence of perfusion defects in the context of precapillary $\mathrm{PH}$. The haemodynamic profile of this patient was remarkable and inconsistent with a diagnosis of CTEPH, given the supranormal cardiac output and, probably due to a hyperdynamic state, elevated PAWP and low SVR. This combination of findings is highly unusual in most forms of $\mathrm{PH}$, where a low cardiac output is usually associated with a high SVR. Exceptions to this rule are PH related to vascular shunts and chronic liver disease, but no signs or symptoms are pointing towards these conditions. Initiation of tadalafil and an endothelin receptor antagonist resulted in a further increase in cardiac output and decrease in SVR, explaining her warm extremities and aggravating her tendency for collapse. A combination of polycythaemia, hepatosplenomegaly and $\mathrm{PH}$ is also found in people living at high altitude. Chronic hypoxia leads to upregulated erythropoietin (EPO) levels and pulmonary vasoconstriction resulting in PH. In fact, blood chemistry revealed an EPO level that was dramatically elevated (see online supplementary table S3). Yet, these EPO levels were found at normoxia. Our patient therefore suffered from secondary erythrocytosis in normoxia. For this reason, routine DNA testing on causes of secondary erythrocytosis was performed.

Medical geneticist: This patient appeared homozygous for a $162 \mathrm{G}>\mathrm{C}$ mutation in exon 1 leading to an amino acid substitution in the Von Hippel-Lindau (VHL) gene. Her parents, being first cousins, were heterozygous for this mutation. There were no mutations found in the JAK2, prolylhydroxylase-2 (EGLN1/ PHD2) and hypoxia inducible factor- $2 \alpha$ (HIF $2 \alpha)$ genes. Mutations in the VHL gene may impair the degradation of HIF $\alpha$ as seen in patients with Chuvash polycythaemia (CP). CP is a rare autosomal recessive disorder first described in the Volga river region in Russia in the 1970 s. $^{1}$ Patients with CP primarily present with thrombosis and vascular abnormalities combined with notable low blood pressures at young age. ${ }^{12}$ The polycythaemia can be explained by the dysregulated oxygen-sensing mechanisms present in normoxia, consequently resulting in transcription of hypoxia-induced genes such as EPO. ${ }^{3}$ In addition, HIF $\alpha$ regulates several genes involved in vasomotor tone such as endothelin-1, $\alpha 1 \mathrm{~B}$-adrenergic receptor and endothelial nitric oxide which could give rise to the development of $\mathrm{PH}^{4}$ (figure 1). Patients with CP also have an increased risk of mortality because of an increased incidence of cerebral vascular events, ${ }^{2}$ which risk could be aggravated by the development of $\mathrm{PH}$.

Resident: In classic VHL tumour predisposition syndrome, heterozygous germ line mutations of VHL are associated with the development of tumours such as renal clear cell carcinoma and vascular tumours. ${ }^{5}$ Does she have an increased risk for developing malignancies as well?

Medical geneticist: None of the studied CP carriers with an Arg200Trp substitution had any VHL syndrome-associated tumours. ${ }^{2}$ This could indicate an absence of predisposition to develop tumours but this has to be confirmed by longitudinal studies. Above that, the mutation found in our patient is located 
at a different site of the gene and therefore no prognosis on predisposition of cancer can be provided.

Pulmonologist 1: The management of $\mathrm{PH}$ with a high cardiac output and low SVR, as seen in patients with CP, is complex. Conventional management of $\mathrm{PH}$ with pulmonary vasodilators may be started, although this increases the hyperdynamic circulatory state and lowers SVR as seen in this patient. Therefore, PAH-specific therapy was reduced. Patients with VHL-induced $\mathrm{PH}$ should be monitored carefully when $\mathrm{PAH}$-specific therapy is initiated. Venesection is a common therapy for polycythaemia and prevents thrombosis, but may also result in iron deficiency. The beneficial effects of venesection in patients with CP are not evident. $^{2}$ Previous research has even shown that iron depletion increases pulmonary artery pressures, ${ }^{6}$ partially because the function of HIF proteins is iron dependent. ${ }^{4}$ The lack of evidence in this field urges further investigation into the role of HIF $\alpha$ and iron status in the development of this type $\mathrm{PH}$ specifically, and may yield insights into the pathophysiology of PAH in general.

In conclusion, we present a patient, in whom a rare mutation in the VHL gene leads to a common phenotype of PH with high cardiac output. Constant transcription of $\mathrm{HIF} \alpha$-regulated genes increases EPO plasma concentration and pulmonary vasomotor tone, leading to secondary erythrocytosis and $\mathrm{PH}$, respectively. This case illustrates the importance of careful assessment and monitoring, and the value of PH expert centres, in the evaluation of patients with unexplained PH. Initiation of PAH-specific therapy may aggravate the hyperdynamic circulatory state, and management of these patients should aim for an equilibrium between severe polycythaemia with hyperviscosity and thrombotic risks, and monitoring elevated pulmonary artery pressures with low SVR.

Twitter Follow Anton Vonk Noordegraaf @Anton Vonk Noordegraaf

Contributors AVN had the idea for the article. LB wrote the first draft of the article. All authors contributed to the final version of the article.

Funding JA was funded by the Dutch Heart Foundation (Grant\# 2014T064).

Competing interests None declared.

Patient consent Obtained.

Provenance and peer review Not commissioned; externally peer reviewed.

Open Access This is an Open Access article distributed in accordance with the Creative Commons Attribution Non Commercial (CC BY-NC 4.0) license, which permits others to distribute, remix, adapt, build upon this work non-commercially, and license their derivative works on different terms, provided the original work is properly cited and the use is non-commercial. See: http://creativecommons.org/ licenses/by-nc/4.0/

\section{REFERENCES}

1 Sergeyeva A, Gordeuk VR, Tokarev YN, et al. Congenital polycythemia in Chuvashia. Blood 1997;89:2148-54.

2 Gordeuk VR, Sergueeva Al, Miasnikova GY, et al. Congenital disorder of oxygen sensing: association of the homozygous Chuvash polycythemia VHL mutation with thrombosis and vascular abnormalities but not tumors. Blood 2004:103:3924-32.

3 Ang SO, Chen H, Gordeuk VR, et al. Endemic polycythemia in Russia: mutation in the VHL gene. Blood Cells Mol Dis 2002:28:57-62.

4 Schofield CJ, Ratcliffe PJ. Oxygen sensing by HIF hydroxylases. Nat Rev Mol Cell Biol 2004:5:343-54.

5 Lonser RR, Glenn GM, Walther M, et al. von Hippel-Lindau disease. Lancet 2003;361:2059-67.

6 Smith TG, Balanos GM, Croft QP, et al. The increase in pulmonary arterial pressure caused by hypoxia depends on iron status. J Physiol 2008;586:5999-6005. 